\title{
Existing Recommendations and Definitions on Disaster Insurance
}

\author{
by Vít Kárník*
}

\section{Introduction}

Every country exposed to natural hazards faces at different intervals in time the problem of covering large losses caused by a natural disaster. It is assumed that a sound natural disaster insurance system could provide an adequate reserve needed for rehabilitation and reconstruction. Insurance can also contribute to mitigation of risks by an appropriate scaling of the rates (premiums) to ensure the application of preventive measures such as for instance earthquake resistant design. In several countries composite disaster insurance schemes function and usually cover several risks. These activities are, however, practised in a rather simple way. It is therefore felt that new efforts are needed to elaborate more effective and economical schemes on a reasonably scientific basis by combining experience accumulated so far at all stages of the process, i.e. from risk assessment to workable insurance and reinsurance schemes. There are still problems of providing better information on natural hazards and on vulnerability of various elements at risk. The available information is not easily convertible to land use and building construction. It may sometimes be difficult to provide adequate insurance cover because the losses may go beyond the resources of the insurance industry.

Insurance is a commercial and financial arrangement dependent on a participant's willingness and ability to pay certain premiums. Where there is not the willingness and ability to pay premiums, little of the discussion about insurance for natural disaster is directly relevant.

Commercial insurance has been recognised as a medium for natural disaster mitigation, but natural disaster has also been recognised as the potential cause of severe losses for the insurance industry.

There are great difficulties in bringing commercial mechanisms designed for frequent small losses, to effectively and profitably relate to rare catastrophic losses. Insurance for traditional risks in life and fire insurance were designed according to the following constraints :

* Chief, Prevention and Support Services Branch, United Nations Office of the Disaster Relief Co-ordinator, Geneva. 
(a) the insured event has to occur with a certain regularity, in a certain period of time ;

(b) The sustained damage must be measurable; it must be possible to calculate the probability of occurrence and the degree of damage ;

(c) The risks must be spread geographically;

(d) The amount of damage must be limited.

Natural disasters, earthquakes and hurricanes especially, do not meet these constraints, and thus cannot normally be dealt with by traditional insurance systems. In certain developed countries, it has been possible to provide for some degree of loss from natural disasters by adding special risks on the back of insurance for fire; and in some cases, governmental subsidisation has ensured that premiums have been kept to acceptable levels.

The participation of governments in direct compensation for natural disaster has been on the increase, but the involvement of public funds for the insurance of private property has itself raised further problems. Many uninsured victims of damage have turned to government funds for assistance, and governments have been increasingly obliged to respond. This in turn has served as a disincentive for the purchase by the public of insurance.

Although the moral and political issues of governmental involvement in insurance for natural disaster may be more easily answered for less developed countries, the financial questions are more difficult. Without money, governments cannot be involved, however much they may want to be.

The necessity of analysing the problems of insurance against earthquake risk at an international level was recognised several years ago. Thus the present establishment of the Working Group on Natural Disaster Insurance under the sponsorship of UNDRO, UNESCO and the Geneva Association represents a continuation of earlier activities of UNESCO and UNDRO which started in 1976.

\section{Meetings on Disaster Insurance sponsored by United Nations agencies}

The development in earthquake insurance can be well demonstrated by quoting the recommendations of three meetings devoted fully or partly to the subject. These recommendations can serve as the background for further deliberations on natural disaster insurance.

\section{1. the UNESCO Intergovernmental Conference on the Assessment and Mitigation of} Earthquake Risk (Paris, 10-19 February 1976), Resolutions 10.02, 10.1.

"The Conference recommends that Member States, in seeking to mitigate seismic risk, adopt optimal combination of the following measures: (a) rules on land use ; (b) building codes; (c) educational and other measures for the improvement of non-engineered buildings not covered by building codes; (d) tax policies and other economic incentives; (e) insurance; (f) planning of emergency action ; (g) planning of relief; (h) relevant research.

The Conference recommends that UNESCO, in co-operation with other United Nations bodies and relevant international organizations, gather experts from all countries 
with earthquake insurance programmes, together with interested experts from countries without such insurance programmes and from major insurance and reinsurance companies, seismologists, earthquake engineers, economists and social scientists, to consider the possibility of developing a workable general framework for the implementation of earthquake insurance and of initiating a long-term programme of studies on earthquake insurance problems."

\section{2. the UNESCO Working Group on the Economic Implications of Earthquake Risk} (Paris, 23-26 August 1977), Recommendations 5.4 and 5.5:

" 5.4 In order to develop a workable general framework for the implementation of earthquake insurance, a step-by-step approach is recommended :

(a) Appropriate rating (appropriate to the risk) and a system of risk-oriented deductibles and partial self-insurance by the insured ("co-insurance") can provide motivation, by economic incentives, for the mitigation of damage due both to earthquake shock and to fire following earthquake, i.e. by the choice of better locations and by improved standards of earthquake engineering. These measures would contribute to an increase in available world insurance capacity, thus enlarging the insurance industry's service to national economies within the given international system of insurance, reinsurance and retrocession (re-insurance).

(b) By more transparency of insurance cover (information on liabilities assumed) and a solution to the problems of setting up catastrophe reserves and of their taxation, world insurance capacity would also be increased.

(c) Studies of the possibilities of improving physical planning techniques and building codes with a view to reducing material damage in addition to saving human lives.

5.5 In addition, the following specific proposals are made for action by Unesco in the near future :

(a) Establish a permanent interdisciplinary committee of experts to co-ordinate progress and the exchange of information on the economic and especially the insurance applications of earthquake studies.

(b) Convene an international conference or seminar on "Earthquake Hazard and Insurance" to be held possibly in Mexico in 1978 or early 1979. The purpose of this meeting would be to bring together a number of experts on a wide range of disciplines related to earthquake hazard and insurance, in order to broaden the scope of discussions on economic losses and on the role of earthquake insurance in abating earthquake risk.

(c) Organize a pilot study by scientists, engineers and the insurance industry of the possible effects of earthquakes on the economy of a given area. A possible choice might be the circum-Caribbean area."

\section{3. the International Seminar on Earthquake Hazards and Insurance (Cocoyoc, Mexico, 4-8 December 1978) sponsored by UNESCO, FIDES, UNAM.}

This Seminar has provided the first forum for discussions on the needs as well as on the limitations imposed by present knowledge on various aspects of earthquake occurrence and earthquake effects. The Seminar proposed to carry out a pilot study. 
The primary goal of the pilot study should be to estimate probable overall losses and the proportion of these losses which were insured. In order to collect information, the study should be made in an area with experience of earthquake damage to as broad as possible a range of structures. It was proposed that both primary and secondary losses should be considered, but analysed separately, bearing in mind that secondary losses may be more difficult to assess. The methodologies developed should be applicable as widely as possible, not simply to the area of the initial pilot study. The analysis of economic losses would require the testing of various evaluation techniques in order to evolve a suitable methodology. An essential aspect of establishing vulnerability relationships is the application of statistical sampling techniques to damage data. The principal emphasis of the study should be economic, but some consideration should be given to life loss.

The areal extent of the study should be kept as small as possible in order to permit the necessary detail, but be big enough to contain a large and varied sample of building types. Building classification should be according to structural design and damage control features (i.e. earthquake resistance, not occupancy).

With regard to the method of risk analysis a probabilistic approach, with careful consideration of the parameters should be used. Some aspects of risk analysis involve the use of data which are difficult to specify probabilistically. Such data should preferably be included in deterministic form.

The pilot study should develop a decision analysis method to illustrate the effective use of the information in actual decision-making and policy analysis.

The following locations are proposed as suitable areas for the pilot study: Costa Rica, El Salvador, Guatemala, Jamaica, Mexico, Trinidad, Venezuela.

Caracas, Guatemala City or Mexico City would be the most suitable choice.

\section{Definitions}

During the presentations at the meeting and during the consecutive discussions several basic terms will be used. It may be useful to repeat some of the basic definitions UNDRO and UNESCO agreed upon during 9-12 July, 1979, at a meeting of experts in Geneva (see the publication "Natural Disasters and Vulnerability Analysis", UNDRO, Geneva, August 1980). First of all -

Risk $(R)$ was defined as the possibility (probability) of loss, and consequently economic risks as the possibility of the loss of property or loss of function of buildings, utilities, etc.

The factors entering into the estimation of risk are value, vulnerability and hazard. The elements at risk are any objects or activities exposed to certain hazards.

Vulnerability $(V)$ is the measure of the proportion of the value which may be lost of an element and can be estimated theoretically or experimentally for a given element at risk for instance for a certain building type. Vulnerability cannot be expressed by a single figure but by a function relating $V$ to the parameter quantifying the hazard. An element may be vulnerable to a certain hazard, but it will not be at risk unless it is exposed to the hazard. 
Hazard $(H)$, in this context, is the probability of occurrence, at a given site or within a given area and within a given period of time, of a phenomenon, natural or man-made, capable of causing a loss of value. Hazard may normally be expressed by a table, graph or map giving the probability of occurrence (or return period) of different levels (grades) of the parameter describing (defining) the hazard. The parameter should be linked to the vulnerability of elements of the ground motion in seismic risk assessment, or the water depth in flood risk assessment.

Consequently, risk to which a given element is exposed is obtained by convolution of the probabilities of all significant levels (grades, intensities) of hazard with vulnerability corresponding to each level. In other words -

$$
\begin{aligned}
& R=H \times V \text { or } \\
& R=\int_{i}^{\text {max }} V_{i} \cdot p \cdot d i \quad i=\text { intensity }
\end{aligned}
$$

If the vulnerability function $V(i)$ is replaced by a step function, we can write

$$
R=\sum V_{i} \cdot p_{i}
$$

The above concepts and definitions have been recommended, however, they are not yet widely used in all disciplines related to disaster insurance. Each paper or each speaker should define which are the basic expressions used. 